\title{
Gene therapy approval may be rocky road for industry
}

Washington. Viagene, the San Diego-based biotechnology company, last week became the first company to gain approval for moving to the next stage of gene therapy trials for an experimental therapy for AIDS.

But the way in which the Recombinant DNA Advisory Committee of the US National Institutes of Health (NIH) reached its decision shows that industry and the RAC may face a bumpy relationship as gene therapy moves down the clinical pipeline.

At present, the RAC has to approve any proposed gene therapy - whether carried out by industry or academic institutions that either receives funds from the NIH, or is carried out at an institution that does so. In addition, the need for public acceptance has encouraged industry to seek RAC approval, even when this has not been legally required.

In moving to phase II trials, however, industry had hoped to deal primarily with the Food and Drug Administration (FDA) and local institutional review boards. Both have responsibilities for safety, and industry believes that this approach would save them time, as well as protect their confidentiality.

Indeed, Sheryl Osborne, director of regulatory affairs for Viagene, says that her company believed that because it had RAC approval for phase I of its protocol, it did not need to submit its proposals to RAC for phase II. It was on this basis that Viagene began late last year to recruit 190 patients at medical centres around the country.

Most of these centres do not receive funds from the NIH. Those that do said that they believed RAC approval was necessary, even though Viagene's protocol was not financed by the NIH. The RAC confirmed that view. As a result, phase II of the trial has gone ahead at centres not receiving NIH funds, while the others are awaiting RAC approval to begin recruitment.

Osborne asked the Office of Recombinant DNA at the NIH to consider their protocol for expedited review. It agreed, and approval was granted last week. But she also wrote to Nelson Wivel, director of ORDA, arguing, that RAC review "should not extend into expanded protocols such as those for phase II and phase III."

Arguing that the safety criteria for inclusion in a phase II trial are very different to those for phase I, the RAC rejected the argument unanimously. This irritated but did not surprise industrialists. "The design of clinical trials is not easy," says Richard Daifuku, responsible for clinical trials at Targeted Genetics. "If you are a leader, you don't want to reveal your whole strategy if you don't have to."

During the same meeting, the RAC took its final vote to approve a simplified review process (consolidated review) for protocols that introduce no new ethical or scientific issues. Until now, all protocols have had undergo a full review by both the FDA and the RAC. The FDA will now go ahead with its usual process, which requires a response within 30 days, while staff at ORDA with three reviewers from the RAC will decide whether the protocol needs full review.

The bureaucratic path to this change began last year when the National Task Force on AIDS Drugs Development identified the dual RAC/FDA process as a barrier to AIDS drug development. Leroy Walters, chairman of the RAC, says that the committee has finally found "a way to streamline the process for the investigator, while keeping public review." Alan Goldhammer, director of technical affairs for the Biotechnology Industries Organisation remains cautious. "That remains to be seen," he says.

Helen Gavaghan

\section{US sets up new bioethics advisory board}

Washington. The US National Science and Technology Council was this week expected to approve plans for a National Biomedical Ethics Advisory Committee (NBAC).

The creation of such a body has the backing of both the Clinton administration and Senator Mark Hatfield (Republican, Oregon), chairman of the Senate Appropriations Committee. Officials expect the committee to be set up towards the end of the year. Its budget will be about $\$ 2$ million, taken from discretionary funds of a number of agencies.

The idea of establishing an ethics advisory committee originated shortly after President Bill Clinton took office, prompted by congressional concern about the lack of policy for the handling genetic information. This will be one of the committee's priorities; another will be to evaluate issues arising from the need to obtain informed consent before carrying out research involving various groups of individuals such as the mentally ill.

The NBAC, which will include scientists, lawyers, philosophers and theologians, will be free to pursue any issue with a wideranging effect on public policy. For example, any unresolved details remaining after the disbandment of an advisory committee specifically set up to look at this issue are likely to pass to NBAC. H.G.

\section{Medical centre cuts staff in preparation for 'managed care'}

San Francisco. The Medical Center at the University of California, Davis, announced last week that 82 employees are to lose their jobs next month in the first phase of a major restructuring aimed at limiting the impact of 'managed care' strategies now sweeping $\mathrm{Cal}$ ifornia's health-care system.

"We absolutely have to do this in order to keep our teaching and research abilities," says Robert Chason, chief operating officer of the Sacramento facility, who warned that some research programmes could be closed. "We can't continue to do everything."

According to Chason, another 90 vacancies will not be filled, and 300 temporary employees will not have their contracts renewed. The hospital employs 10,000 staff, and has an annual budget of $\$ 368$ million.

Chason says that the hospital is having to reorganize in order to attract patients and reduce costs as managed care plans overtake medical insurance throughout the state. Under managed care, primary care physicians become the "gatekeepers" for patients, directing referrals to specialists and turning to an advisory board to set treatment guidelines.

As networks of service providers begin to control patient care, Davis must link up with primary care physicians and create its own network to survive, says Chason. The medical centre has bought two primary care practices in nearby towns, and aims to add 100 primary care physicians over the next five years. Some of the new doctors are likely to be recruited from the Davis medical school, well known for primary care training.

The hospital is also planning affiliations with other hospitals and has established links to rural physicians extending to the Oregon border. Rural areas are largely overlooked by major hospitals, says Chason.

With federal and state dollars shrinking, the UC-Davis Medical Center has to compete more effectively with the private sector, he says. He estimated that the hospital must retain 175,000 patients within its system to be able to continue its teaching and research functions.

An advisory board that now links the medical school and hospital will be considering ways to integrate the two and set priorities. Physicians at the hospital have also been charged with reducing costs in a variety of ways, including reducing the use of laboratory and X-ray procedures.

University of California teaching hospitals in San Diego, San Francisco and Los Angeles are already considering similar changes. Chason predicts that medical schools throughout the country will face the same challenge as the managed care approach spreads.

Sally Lehrman 